\title{
A insuperável dimensão simbólica da vida Negação e afirmação do querer nas filosofias de Schopenhauer e Nietzsche
}

\author{
The insuperable symbolic dimension of life \\ Denial and life-affirmation of the will in the philosophies \\ of Schopenhauer and Nietzsche
}

Roberto de Almeida Pereira de Barros*

Universidade Federal do Pará (UFPA), Belém, PA, Brasil

\section{Resumo}

Este texto aborda as ideias de negação e afirmação da vida sob as óticas de Schopenhauer e Nietzsche a partir do pressuposto de que as considerações de ambos implicam intransponíveis considerações simbólica destas noções. Não se trata de confrontar os autores, mas antes de mostrar como em suas filosofias podem ser antevistas considerações sobre a significação da atividade simbólica humana.

Palavras-chave: Vida. Vontade. Afirmação. Negação. 


\section{Abstract}

This text approaches the ideas of denial and affirmation of life under the optics of Schopenhauer and Nietzsche from the assumption that the considerations of both implies insurmountable symbolic considerations of these notions. It is not a matter of confronting the authors, but rather of showing how in their philosophies considerations of the meaning of human symbolic activity may be foregrounded.

Keywords: Life. Will. Affirmation. Denial.

\section{Introdução}

A contemporaneidade, ainda marcada pelo forte impacto da ascensão das ciências nos últimos dois séculos, apresenta acentuadamente a tendência de interpretar a racionalidade humana em uma ótica naturalista e enquanto resultado de alterações genético-orgânicas. Por conseguinte, este direcionamento se contrapôs fortemente às interpretações filosóficas dualistas, pautadas em uma diferenciação entre razão e corpo. Decisivamente a partir da publicação das conclusões de Darwin, estabeleceu-se o pressuposto de interpretar mutações genéticas como sendo o pano de fundo de variações orgânicas úteis ${ }^{1}$, assim como a ideia de que mutações advém das seleções natural e sexual e da descendência, ou, nas palavras do naturalista inglês:

Eu poderia afirmar, que a seleção natural está examinando diária e a toda hora, em todo o mundo entre cada variação mesmo a menor, rejeitando aquela que é má, preservando e assimilando (adding up) tudo que é bom, trabalhando silenciosa e insensivelmente (insensibly) onde quer que e sempre que há oportunidade

Anterior a Darwin, Lamarck argumentava no sentido de geração espontânea por excitação de órgãos em adaptação as exigências do meio e a partir disso formulou a teoria da herança das características adquiridas (inheritance of acquired characteristics) para explicar a transmissão de determinadas características. 
para o desenvolvimento de algum ser orgânico em relação às suas condições de vida, orgânicas e inorgânicas² .

As teorias de Darwin foram decisivas para o estabelecimento da interpretação monista da relação entre corpo e mente em detrimento da interpretação dualista proposta pela filosofia. Um de seus impactos mais significativos foi então a naturalização da racionalidade humana e de sua interpretação como característica específica da espécie. Esta mudança fez surgir um novo horizonte de investigação acerca da função e dos modos de atuação da racionalidade, que alcança a atualidade com grande significação.

Exemplarmente pode-se mencionar aqui as pesquisas de António Damásio, adequadas "a organismos em transformação evolucionária pela seleção natural" ${ }^{3}$. Estas pesquisas mencionam a respeito da sobrevivência de organismos, a existência de circuitos neuronais para pulsões e impulsos ${ }^{4}$, coadunado com um segundo aspecto que gostaríamos de mencionar com respeito à racionalidade humana e a sua interpretação enquanto resultado de uma alteração genético-orgânica e a partir da qual desenvolvem-se mente e consciência como produtos do cérebro, portanto, como tendo uma origem orgânica, mas caracterizados por significativa função simbólica. Tratava-se não de tentar reduzir a mente ou a consciência à regularidade de reações orgânicas, mas de rever a ordem interpretativa usada até então para, partindo disso, reconsiderar as dimensões da atividade mental humana. Para Damásio é o cérebro que constrói a mente consciente a partir dos sentimentos primordiais, do "protoself", chegando ao "self-objeto", "uma coleção dinâmica de processos neurais integrados, centrada na representação do corpo vivo, que encontra expressão em uma coleção dinâmica de processos mentais integrados" ${ }^{\prime}$, do qual decorre o self-sujeito, "como conhecedor, como o "eu", muito mais complexo e difícil de captar, mas que "tem seu alicerce no self-objeto" 6 .

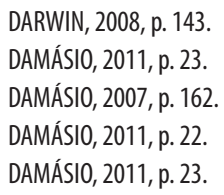


Para que a mente se torne consciente, um conhecedor, seja lá como for que o chamemos - self, experienciado, protagonista -, precisa ser gerado no cérebro. Quando o cérebro consegue introduzir um conhecedor na mente, ocorre a subjetividade ${ }^{7}$.

A partir deste ponto de vista, a consciência pode ser interpretada como "uma organização de conteúdos mentais, centrada no organismo que produz e motiva esses conteúdos"8 e que vai para além do organismo. Influenciado pela posição de Searle, Damásio adota o ponto de vista de que a subjetividade é gerada a partir de trocas imagéticas entre os selfs e o corpo, e que este é o pressuposto decisivo para a compreensão da consciência.

À luz destes fatos, o melhor modo de conceber o corpo é como uma rocha sobre a qual se assenta o protosself, enquanto o protosself é o eixo em torno do qual se gera a mente consciente ${ }^{9}$.

Outra interpretação naturalista recente é a de Yuval Noah Harari, que em seu livro Sapiens - uma breve história da humanidade (2014) menciona uma "revolução cognitiva" do homo sapiens, ocorrida cerca de 70.000 anos atrás, que possibilitou o início da superioridade desta sobre as demais espécies humanoides existentes. Para explicar este acontecimento Harari se refere a uma "mutação genética acidental"10, devido ela não ter ocorrido, por exemplo, entre os Neandertais ${ }^{11}$. Independentemente do caráter hipotético deste esclarecimento, o historiador israelense busca nomear com o pressuposto o "surgimento de novas formas de pensar e comunicar", que se tornariam responsáveis pela supremacia dos sapiens. Harari apresenta duas hipóteses interpretativas para esta evolução do homo sapiens, a versatilidade da linguagem em diferenciação as formas de comunicação dos outros homos, que meramente cumpririam funções designativas imediatas e, a

\footnotetext{
Idem, p. 25.

Idem, p. 23.

Idem, p. 25.

No aforismo 123 de Aurora Nietzsche escreve: "Razão (Vernunft). - Com a razão veio ao mundo? De forma barata e de modo não racional (unvernünftige), por meio de um acidente. É necessário adivinhar, como um enigma" KSA 3, 123.

11 HARARI, 2014, p. 22.
} 
ampliação do compartilhar de informações, fator essencial para a cooperação, portanto, para a sobrevivência e reprodução de grupos. Isso teria possibilitado desde a identificação e exclusão de comportamentos coletivamente inadequados por meio da fofoca (Gossip) mas também, decisivamente, uma ampliação da capacidade de "transmitir informações sobre coisas que não existem"12. Em outras palavras, o historiador israelense se refere ao surgimento da ficção, com grandes vantagens coletivas e de sobrevivência, o que demostra grandes proximidades com alguns posicionamentos das filosofias de Nietzsche e de Schopenhauer com respeito à significação vital do simbolismo.

É este o ponto que as considerações feitas aqui, as quais estão voltadas às abordagens de Schopenhauer e de Nietzsche acerca da negação e afirmação da vida, que objetiva-se indicar. Sob uma ótica contemporânea é possível, apesar dos distanciamentos, antever já nestes dois autores aspectos presentes em abordagens atuais sobre o conhecimento humano e os aspectos implícitos nele. Mesmo compreendendo-os como críticos do reducionismo materialista das ciências naturais, em Schopenhauer e em Nietzsche ocorrem deslocamentos teóricos decisivos no que se refere às discussões epistemológicas e gnosiológicas precedentes. Para ambos, a consciência e seus produtos não podem mais ser vistas como desvinculados e não influenciados pelo organismo e isso repercute direta e incisivamente em concepções capitais relativas a ela. A imprescindibilidade do corpo, de suas regulações e necessidades para a análise de padrões mentais mais elementares postulada por eles significam argumentos primazes mobilizados para pôr em questão os pressupostos de liberdade e de autodeterminação da instância racional postulados pela tradição racionalista. Em Schopenhauer a concepção metafísica, com justificação imanentista subordina, de forma peremptória, entendimento e razão à vontade em sua manifestação fenomênica ao corpo e afirma que o princípio de individuação, tanto do sujeito como das suas representações, constitui apenas limitações intuitivas da constituição fisiológica humana. Para o filósofo de Frankfurt, se intuitivamente tendemos a interpretar o mundo identificando identidades a

12 HARARI, 2014, p. 23. 
partir da convicção da identidade da consciência, isso se deve precisamente pela intermediação do corpo, que determinando o entendimento o faz organizar os dados sensíveis em representações, por meio das intuições e apenas o esforço racional mais elevado pode ultrapassar esta determinação, que em última instância é ilusória.

Nietzsche inicialmente acompanha a tendência imanentista de Schopenhauer ${ }^{13}$. Reafirma a conexão entre corpo e racionalidade e recusa, afirmando como meramente moral, todo pressuposto de autonomia e neutralidade desta. É precisamente a abertura de um âmbito valorativo de investigação - todavia pautado em uma análise fisiopsicológica dos pressupostos metafísicos - que afasta Nietzsche da perspectiva metafísica de Schopenhauer e o leva à formulação de uma outra interpretação volitiva do mundo como hipótese interpretativa $^{14}$. Se para Schopenhauer, vinculado à dicotomia kantiana entre coisa em si e fenômeno, a efetividade em sua totalidade não pode ser conhecida, pois as categorias e intuições do sujeito do conhecimento se limitam às representações deste ao âmbito do mundo percebido e particularizado, este mundo, interpretado até o seu limite cognoscível sob o ponto de vista material, resulta como carente de sentido, pois esta perspectiva não possibilita que se compreenda o princípio que gera a sua incessante dinamicidade. Com efeito, Schopenhauer se propõe a "elucidar o enigma do mundo"15, o que o leva a ultrapassar os limites da especulação naturalista e propor uma nova interpretação metafísica deste, esta, no entanto, absolutamente justificada enquanto explicação imanente. Desse modo, ele formula o princípio interpretativo da vontade, dado sua compreensão do incessante traço de incompletude e cobiça (Verlangen) constatável no mundo. Relativo a este tema, chega-se a um aspecto central e de grande complexidade do pensamento schopenhaueriano. Ao mesmo tempo que afirma a eterna

13 Muito embora o termo imanência não se faça presente no conjunto do legado dos escritos de Nietzsche, nestes podem ser encontradas inúmeras referências que balizam esta afirmação. A sua filosofia, decisivamente no que concerne ao conhecimento, se atém a uma perspectiva clara de interpretação da efetividade em suas múltiplas dimensões e que não pode se afastar dela, sendo este um dos pontos decisivos de sua crítica à metafísica.

14 NIETZSCHE, 1998, p. 54-55.

15 SCHOPENHAUER, A. O mundo como Vontade e Representação I (SCHOPENHAUER. WWV I/MV I). Leizig: F. A. Brockhaus, §27, p. 201. 
incompletude do mundo como forma de elucidar o caráter destrutivo e cambiável deste, decorrente da eterna insaciabilidade da vontade no seu esforço de objetivação, o filósofo menciona o caráter perene das ideias enquanto "NÍVEIS (STUFE) determinados e estáveis da OBJETIVAÇÃO DA VONTADE"16, Schopenhauer parece assim mobilizar pressupostos que aparentemente parecem ser conflitantes entre si. A abordagem a seguir busca, em um primeiro momento, analisar esta questão e o seu desdobramento na filosofia de Schopenhauer, a partir da interpretação do princípio da negação da vontade de viver (Verneinung des Willens zum Leben) por meio da contemplação objetiva e supra individual do mundo, direcionando, entretanto, a discussão para uma consideração do significado simbólico passível de ser interpretado na concepção schopenhaueriana. Em um segundo momento, serão analisadas a crítica de Nietzsche relativas à sua interpretação do niilismo e a sua perspectiva afirmação (Bejahung) da vida, também sob a ótica da sua dimensão simbólica desta concepção.

\section{Formalismo e limites interpretativos em Schopenhauer}

A assimilação restrita de determinados aspectos da filosofia kantiana, notadamente os relativos ao caráter limitado das representações produzidas pela consciência humana e, a partir disso, do conhecimento humano do mundo fenomênico, leva Schopenhauer a assimilar uma tendência que perpassa todo o pensamento filosófico alemão a partir de Kant, a da denúncia do reducionismo das ciências, presas a pressupostos de juntificação, pautados decisivamente na referencialidade material. Como mormente conhecido, Kant afirma a impossibilidade da metafísica em vir a ser considerada como ciência, mas também a limitação do pensamento científico, restrito ao às capacidades representativas do sujeito do conhecimento. Em sua filosofia isso resulta no estabelecimento de uma dimensão fronteiriça, negativa, tanto para

16 SCHOPENHAUER, WWV I/MVI§ 25, p. 187. 
a metafísica, quanto para o conhecimento científico, que não podem mais ultrapassar os limites da referencialidade intuitiva.

A consideração de Schopenhauer destas questões associa três fatores, como mencionado, a assimilação da restrição kantiana atribuída às ciências e, ao mesmo tempo, a naturalização da estrutura lógico categorial da consciência. A isso acrescente-se o esforço de reestabelecer uma interpretação metafísica do mundo fenomênico, mas que, ainda em um certo "espírito" kantiano, deve justificar-se por meio de um esclarecimento imanente do mundo. A intenção de Schopenhauer é de tentar ampliar a compreensão da efetividade para além dos padrões de referencialidade. Esta pretensão é levada a cabo primeiramente a partir da inserção da problemática do corpo para esclarecer o funcionamento e limitações da estrutura intuitivo-categorial das representações da consciência ${ }^{17}$. Por meio do corpo lhe é possível formular uma interpretação da tendência insuperável no homem, mas criticável sob o ponto de vista do pensamento abstrato, de identificação pontual, singularizada tanto do eu como das representações. Neste sentido, a identidade e o princípio de razão são considerados por ele como traços advindos da compreensão individualizada e intuitiva da ação direta da vontade sobre o corpo, que enquanto condição de conhecimento a posteriori da vontade e submetido a ela, atua na mediação do entendimento no momento do ato de interpretação do sujeito do conhecimento e, com isso, torna-se fator determinante na forma causal de interpretação das representações, entendidas de forma também particularizada.

O pressuposto metafísico da vontade possibilita a Schopenhauer abordar a separação kantiana entre noumenon e fenômeno, entre coisa em si e representação, em uma nova perspectiva. Ao afirmar que é "só na reflexão que o agir e o querer se diferenciam" e, portanto, que é apenas na representação que a individuação tem um sentido, Schopenhauer pressupõe que a interpretação pautada em identificação individual e sucessão é insustentável sob a perspectiva metafísica da vontade como princípio último de elucidação do mundo, para a qual descontinuidades e delimitações não são possíveis. Para ele, a

17 FONSECA, 2016, p. 39. 
manifestação diferenciada do mundo fenomênico não consiste em argumento contrário a esta interpretação, pois seu ponto de análise se pauta na constância e similaridade imanente das manifestações fenomênicas indicando-as como regidas pela volição, o que o possibilita afirmar a unidade da vontade ${ }^{18}$. $\mathrm{O}$ movimento incessante e a ausência de qualquer indicador de uma finalidade para o mundo são aspetos que compõem o grupo de argumentos, mobilizados pelo filósofo, para afirmar que relativo à vontade não é possível afirmar nem descontinuidade nem finalidade e que ela é sempre a totalidade que a constitui e que se manifesta livremente no mundo

A VONTADE como coisa em si é plenamente diferente de sua manifestação e totalmente livre das formas desta e nas quais adentra (eingeht) quando se manifesta; formas, portanto, que se aplicam somente à objetividade e que lhe são mesmo estranhas ${ }^{19}$.

Sob o ponto de vista de uma teoria do conhecimento, Schopenhauer assimila criticamente o formalismo dos limites impostos por Kant ao conhecimento. Segundo ele, o autor da Crítica da razão pura teria corretamente compreendido o limite dos conceitos fundados na intuição (Anschauung), mas teria dado pouca atenção ao significado dos limites desta compreensão sob o ponto de vista da própria percepção intuitiva, não conceitual, da vontade, cuja origem é o corpo.

Excetuando-se meu próprio corpo (Leib), é por mim conhecido apenas um lado de todas as coisas, o da representação: sua essência íntima permanece obstada para mim e um profundo enigma, mesmo que eu conhecesse todas as causas das quais decorrem as suas mudanças. Somente da comparação com aquilo que se passa em mim quando meu corpo executa uma ação após um motivo me mover - e que é a essência íntima da minha própria mudança determinada por fundamentos externos - posso adquirir intelecção (Einsicht) do modo como os corpos (Körper) sem vida mudam por meio de causas e assim compreender o que é a sua essência

18 SCHOPENHAUER, WWV I/MV I 23, p. 174.

19 Idem, p. 166. 
íntima, de cuja manifestação me dá o conhecimento da causa da simples regra da entrada no tempo e espaço e nada mais ${ }^{20}$.

Se a coisa em si não pode ser conhecida, como Kant já o afirmara, a percepção volitiva da essência do mundo, que jamais será conhecimento dela, pode fornecer uma ampliada percepção da essência do mundo. Esta intuição extrapola a compreensão restrita à compreensão da estrutura categorial e dos processos de subsunção de dados sensórios, conceituação e dialéticos, a partir dos quais as representações do mundo são construídas. Apenas a metafísica, sustentada pela percepção imediada do mundo e pautada em um dogmatismo imanente, pode ultrapassar tanto o reducionismo materialista das ciências, quanto a limitação conceitual da filosofia kantiana e fornecer uma interpretação uma do existente.

\section{A aparente contradição da vontade nas suas manifestações fenomenais}

Visto sob a ótica da metafísica da vontade, para Schopenhauer o mundo da representação é resultado do impulso de objetivação da vontade e constituído pelos seus graus de objetivação, que vão dos mais rudimentares, tais como as objetivações do mundo inorgânico e dos organismos elementares, passando pelo homem e chegando às ideias, as mais elevadas formas de representação. Ocorre, todavia, na interpretação fenomenal do mundo orgânico uma discrepância entre os graus de manifestação da vontade. Por um lado, ela se manifesta primeiramente como ímpeto (Drang), que resulta em unidades volitivas norteadas pelo instinto egoísta de sobrevivência, mas por último ela se manifesta na individuação que produz o mundo da representação, enquanto "imagem (Abbild) de sua própria essência" ${ }^{21}$ e que também representa a universalidade e conexão de suas manifestações na beleza estética e nas ideias. Mesmo entre as ideias este antagonismo parece existir e exprimir uma contradição das ideias entre si, pois a

20 SCHOPENHAUER, WWV I/MV I $\$ 24$, p. 182.

21 SCHOPENHAUER, WWV I/MV I 27, p. 213. 
ação destrutiva entre as individualidades tende a ascender para graus de manifestação mais perenes. Schopenhauer fala mesmo de uma "essencial cisão (Entzweiung) da vontade consigo mesma"22, mas indica com isso a vontade em sua representação espaço-temporal, para a qual rege a "luta de todas as aparências da vontade entre si inclusive nos mais baixos níveis da objetivação da vontade" ${ }^{23}$. Esta contradição, todavia, precisa ser amplamente considerada, pois para Schopenhauer ela é decorrente da compreensão do fenômeno por meio da consciência e do princípio de individuação que é próprio do intelecto humano. A compreensão do mundo pelo sujeito cognoscente, para além das funções vegetativas, consiste em uma forma de mediação com respeito à percepção intuitiva e, por isso, fornece apenas uma restrita compreensão da essência do mundo, que pode ser abstratamente compreendida a partir da compreensão das limitações desta própria forma de representação, pois "representação, enquanto tal, já pressupõe uma forma, a saber, objeto e sujeito, destarte é relativa" ${ }^{24}$. Estes pressupostos expandem-se à toda filosofia de Schopenhauer e consistem em aspectos de grande significação para a sua filosofia moral, que implica no tema da "autossupressão" da vontade ou da "resignação", mencionada no final do $\S 52$ do terceiro livro de O Mundo como vontade e representação (MV), embora, como indicado neste mesmo trecho, abordado mais especificamente no quarto e último livro da obra.

As indicações apresentadas previamente no terceiro livro, e resumidamente indicadas aqui, consistem em pressupostos elementares para a consideração deste tema e de suas possibilidades argumentativas. Ao afirmar que tendo a vontade que "devorar a si mesma, já que nada existe de exterior a ela, e que ela é uma "vontade faminta", Schopenhauer pressupõe os limites desta afirmação pautada no pressuposto do Caráter Inteligível, que é a compreensão mediada pela racionalidade de um "ato indiviso e extratemporal da vontade" 25 . O caráter inteligível é produto racionalidade, entendida como responsável

\footnotetext{
22 SCHOPENHAUER, WWV I/MV I 27 , p. 208.

23 SCHOPENHAUER, WWV I/MV I § 27, p. 209.

24 SCHOPENHAUER, WWV I/MV I§ 29, p. 227.

25 SCHOPENHAUER, (PP/PP) II § 28, p. 219.
} 
pela "capacidade de dissimulação" (Verstellung) que é própria do ser humano e que é uma manifestação de sua vontade de vida mediada pela razão. $\mathrm{O}$ caráter inteligível se baseia, portanto, no princípio de razão, na compreensão causal do fenômeno, de seu ato empírico, determinando-o enquanto princípio de inteligibilidade. Dada a sua limitação em abarcar os atos originários de sua objetivação, ele apenas pode reconstruir retroativamente a causalidade inteligível e por isso não pode apreender na sua totalidade a aparente contradição entre a unidade da vontade, a sua "concordância consigo mesma" e o "conflito interno" (innere Widerstreit) inerente ao mundo fenomênico ${ }^{26}$.

Igualmente, cada ato particular da vontade de um indivíduo cognoscente (que é apenas aparência da vontade como coisa em si) necessita de um motivo, sem o qual o ato nunca ocorreria: mas, assim como a causa material contém apenas a determinação sob a qual neste tempo, neste lugar, nesta matéria uma exteriorização desta ou daquela força natural necessita ocorrer, também o motivo determina o ato da vontade completamente particular de um ser cognoscente neste tempo, neste lugar, nestas condições como plena singularidade, de modo algum, porém, determina o que aquele ser propriamente quer e de que maneira; tal ser é exteriorização de seu caráter inteligível, o qual, como a vontade mesma, a coisa em si, é sem fundamento, que se encontra fora do âmbito do princípio de razão ${ }^{27}$.

Com efeito, a abordagem da questão da limitação da causalidade referente ao mundo orgânico é significativa na interpretação de Schopenhauer e retomada no início do quarto livro de $O$ mundo como vontade e representação, mas então vinculada a uma perspectiva prática da compreensão filosófica do mundo e da vida humana. A ação, afirma o filósofo, só pode ser considerada de forma limitada, "como resultado da totalidade do conteúdo da investigação" e por isso, com relação a ela e mesmo considerando o insuperável caráter teórico da filosofia no que se refere à ação, deve se limitar a descrever e se abster de prescrever ${ }^{28}$.

26 SCHOPENHAUER, WWV I/MV I 228, p. 226.

27 SCHOPENHAUER, WWV I/MVI $\$ 29$, p. 228.

28 SCHOPENHAUER, WWV I/MV I 553, p. 357. 
Esta descrição comporta uma interpretação que, como já mencionado, é cônscia de seus limites especulativos e caráter intuitivo. Trata-se de uma interpretação da vida, que é a manifestação, espelho (Spiegel) e objetividade da própria vontade ${ }^{29}$ e que por isso se apresenta como contraditória para o entendimento e mesmo para a razão que, muito embora mobilize ideias abstratas ${ }^{30}$ e logre ultrapassar a referencialidade individual temporal, remetendo a um ponto de vista superior, de onde temos em mira não o particular, mas o universal, não é apta a compreender a infinitude e liberdade da vontade. Se em sua manifestação fenomênica a vontade afirma a si mesma e se mostra como "vontade de vida" e apesar de que, ao possibilitar a superação dos pressupostos de singularidade e de finitude dos fenômenos por meio do conhecimento, implique em "completa AFIRMAÇÃO DA VONTADE DE VIDA", ainda assim a razão, ao evidenciar a essência do mundo por meio da apreensão das ideias, resulta em uma NEGAÇÃO DA VIDA ${ }^{31}$, entretanto unicamente sob o ponto de vista da individuação, pois é sob uma perspectiva prática que o limite de interseção da razão possibilita a ela se tornar uma forma de apaziguamento da vontade.

A NEGAÇÃO DA VONTADE DE VIVER mostra-se quando no conhecimento finda-se a vontade, no que, portanto, não mais atua a manifestação individual como MOTIVO (MOTIVE) do querer, porém o total conhecimento, pela compreensão da ideia, da essência do mundo, que a vontade reflete, e se torna QUIETIVO (Quietiv) da vontade e assim a vontade suprime a si mesma livremente ${ }^{32}$.

Este mesmo princípio atua também na arte e deve ser bem observado para que se compreenda que a contradição da manifestação volitiva consigo mesma é apenas aparente, que não resiste a um olhar para além (durchschauen) do principium individuationis, o

29 SCHOPENHAUER, WWV I/MV I 554, p. 562.

30 SCHOPENHAUER, WWV II/MV II 29, p. 426.

31 SCHOPENHAUER, WWV I/MV I 554, p. 374.

32 "der Wille frei sich selbst aufhebt". Schopenhauer, WWV I/MV I § 54, p. 374. 
que possibilita "uma manifestação efetiva da liberdade própria da vontade enquanto coisa em si" $^{\prime 3}$.

Neste sentido, Schopenhauer indica que a questão da liberdade humana ante a vontade só pode então ser considerada de forma negativa. O ser humano, na sua diferenciação de todas as demais aparências fenomenais da vontade pode ser livre, mas apenas em casos excepcionais e por meio da "supressão da vontade", quando considerada unicamente a vontade fenomenal, por conseguinte apenas por meio do ultrapassamento da vontade considerada individualmente, dada a impossibilidade de entendimento e razão poderem interferir na essência do mundo.

Provisoriamente, indica-se aqui de modo geral como o homem diferencia-se de todas as demais manifestações (Erscheinungen) da vontade, dado que a liberdade, isto é, a independência do princípio de razão, que se aplica apenas à vontade como coisa em si e contradiz a manifestação, poder no seu caso também possivelmente ocorrer nesta, onde ela então necessariamente se apresenta como uma contradição da manifestação consigo mesma ${ }^{34}$.

As dificuldades de compreensão deste posicionamento são evidenciadas pelo próprio filósofo, e elas só podem ser minimamente superadas se compreendidos alguns pontos centrais: 1. A contradição está restrita ao fenômeno e à forma com que ela se apresenta para a consciência cognoscente. 2. A vontade não pode ser suprimida por uma manifestação fenomenal, que é necessariamente produto submetido da vontade ${ }^{35}$ e, 3 . A compreensão racional do mundo é ela própria uma manifestação da vontade que ultrapassou a individualidade e, no mundo fenomênico, se aproximou ao máximo dos graus mais elevados de objetividade da vontade ${ }^{36}$.

Por conseguinte, a supressão da vontade parece só poder ser pensada se relativa a vontade fenomênica, que jamais é livre, mas sim determinada desde o nascimento e permanece essencialmente

33 SCHOPENHAUER, WWV I/MV I 555, p. 394.

34 SCHOPENHAUER, WWV I/MV I 555, p. 378.

35 SCHOPENHAUER, WWV I/MV I 555, p. 382.

36 Portanto, de negação da vontade. Cf. BARBOSA, J. Negação da vontade e significado moral do mundo, 2015. p. 187. 
a mesma até o fim da vida. A razão, pressuposta a sua gradação fenomênica, pode agir sobre manifestação da vontade com motivos, mas "jamais mudar a vontade mesma: pois tem poder sobre ela apenas sob a pressuposição de que a mesma é exatamente tal como é" ${ }^{\prime 37}$. Apenas a mudança de direção da aspiração da vontade é possível, "isto é, fazer com que procure por um caminho diferente o que invariavelmente procura" 38 , o que Schopenhauer chama de "DECISÃO ELETIVA" (WAHLENTSCHEIDUNG) ou "capacidade de deliberação" (Deliberatiosnfährigkeit) $^{39}$. A razão influencia a ação, mas não a sua determinação, o que significa dizer que as figuras primordiais nas quais a vontade transcende a volição mais bruta e parece negar a si mesma só ocorrem por uma determinação única e necessária da vontade, que é a base de todo fenômeno humano ${ }^{40}$.

Tendo em vista a imperscrutabilidade da vontade, a contradição indicada é delimitada ao mundo fenomênico, pois a vontade de negação da vida, ou a vontade de nada permanece ainda a vontade, porém redirecionadas para as mais elevadas manifestações desta, as ideias que, tal como todos os demais fenômenos da vontade, são geradas pelo conflito interno da vontade consigo mesma. Considerados estes aspectos, a aspiração pelo nada, indicada no último livro da obra capital do filósofo, parece poder ser considerada como uma noção decisivamente propositiva e não efetiva, dado ela apresentar não apenas dificuldades imanentes, mas de expressão do que venha a ser ${ }^{41}$.

\section{As dimensões simbólicas da Representação e do Nada}

A lapidar afirmação inicial de $O$ mundo como vontade e representação, "O mundo é minha representação: - esta é uma verdade que é válida em relação a cada ser vivente e cognoscente, embora apenas o

37 SCHOPENHAUER, WWV I/MV I 555, p. 386.

38 Ibidem.

39 Idem, p. 390.

$40 \quad$ Idem, p. 384.

41 FONSECA, 2016, p. 43. 
homem possa trazê-la à consciência refletida e abstrata" 42 é bastante indicativa no que se refere à consideração da representação simbólica na filosofia de Schopenhauer problematizada aqui e que possui importância central na reflexão de Nietzsche.

Enquanto representação, o mundo para Schopenhauer é, decisivamente, figuração (gestalten) de uma consciência limitada pelas suas próprias formas de compreensão. A capacidade de compreensão humana abarca várias dimensões interligadas, a corpórea, dos dados sensíveis, a intuitiva (entendimento), que identifica os objetos e o próprio sujeito mediante as intuições apriorísticas de tempo, espaço e causalidade e a dimensão racional, que mobiliza abstratamente os conceitos. O homem é o único ser capaz de ultrapassar a imediaticidade e compreender a existência de forma mais ampla, o que lhe possibilita entender e refletir sobre o caráter brutal da existência, mas também possuir a possibilidade da transcendência. É dessa forma que noções como liberdade, felicidade, justiça, paz e BOM ABSOLUTO podem se fazer presentes no ideário do homem, sem que em nenhum momento haja um correlato efetivo para elas.

Segundo o anteriormente dito, o BOM (GUTE) é, segundo o seu conceito, $\tau \omega v \pi \varrho 0 \varsigma \tau \mathrm{L}$, portanto todo bem, essencialmente relativo: pois ele tem sua essência apenas em relação à vontade concupiscente. BOM ABSOLUTO é por isso uma contradição: O mais alto BEM (GUT), summum bonum, significa o mesmo, própria e precisamente uma satisfação final da vontade, segundo a qual nenhuma vontade nova se manifeste, um motivo último, cujo alcance significaria uma satisfação indestrutível da vontade. Segundo a nossa consideração neste quarto livro, algo assim não é pensável. A vontade muito menos pode por conta de alguma satisfação cessar de continuamente iniciar novamente a querer, como se o tempo pudesse findar ou começar: uma duradoura, plenamente satisfatória consumação para o seu ambicionar (Streben) não existe para ela ${ }^{43}$.

42 SCHOPENHAUER, WWV I/MVI $\$ 1$, p. 31.

43 SCHOPENHAUER, WWV I/MVI $\S 65$, p. 468. 
Desse modo, Schopenhauer indica uma atuação ficcional, simbólica, do intelecto atuante na produção das representações do mundo, que se manifesta em dimensões superiores, como na arte e no conhecimento das ideias. Esta dimensão também possui graus de abstração, que são justificados pelo pressuposto da ambição da vontade por manifestações estáveis, mas que, todavia, serão sempre apenas representações produzidas por um sujeito. As configurações volitivas requeridas por ela são bastante raras e consistem em manifestações da vontade com acesso a graus superiores de objetivação. Inversamente proporcional à compreensão da essência da vida e do mundo por intermédio da ideia, o homem preso à individualidade, à sua momentaneidade delimitada e ao "sofrimento momentâneo", interpreta esta condição como única efetividade, e se volta à tentativa de gozo e desfrute da vida, o que para Schopenhauer o remete rapidamente ao sofrimento, pois a vontade não pode ser apaziguada $^{44}$ e assim a afirmação (Bejahung) da vontade de vida (Wille zum Leben) leva invariavelmente ao sofrimento ${ }^{45}$. Em ambos os tipos de manifestações da vontade, nas suas infinitas multiplicidade e diferenças, é imprescindível a dimensão simbólica, caracterizada pela forma de representação do sujeito e pelas perspectivas de negação ou de afirmação da vontade de viver. O gênio, o santo e o puro sujeito do conhecimento, nos períodos de contemplação das ideias, não são mais indivíduos, mas volições voltadas para as mais elevadas manifestações da vontade. Neles, o querer se torna o nada querer do mundo da vida na sua dimensão sensorial, tornando-se com isso querer o nada querer. Estas manifestações volitivas não podem ser adquiridas, pois o contemplar a vontade por meio das ideias significaria, nestes casos, a alteração de uma determinação volitiva prévia da vontade ${ }^{46}$.

Para Schopenhauer, apenas por ilusão moral podemos acreditar que toda preocupação ética, com pretensão à redenção, ou mesmo a própria compaixão para com o outro deixam de conter o egoísmo próprio da vontade quando mediados pelo intelecto. Todavia, em homens

44 SCHOPENHAUER, WWV I/MV I § 63, p. 546.

45 Idem, p. 458.

46 CARUS, 2016, p. 25. 
elevados pelo desinteresse pela imediaticidade fenomênica, tais posturas ocorrem devido desvio do interesse e não de forma direta, elas são mediadas pelo entendimento ${ }^{47}$, que permanece sendo manifestação da vontade, haja visto não haver nenhuma possibilidade de alteração da essência da volição, pois "em toda abstrata ocupação do espírito (Gesitesbeschäftigung) a vontade é o timão (Lenker)" ${ }^{\prime 4}$. A diferença entre estes casos e os indivíduos maus, caracterizados pela ação direta e irrefletida do egoísmo, é que nestes a volição mantém-se voltada aos interesses imediatos do querente.

Como anteriormente vimos o ódio e a maldade condicionados pelo egoísmo e este repousar na conciencidade do conhecimento (Befangenseyn der Erkentniß) do principium individuationis; também achamos, logo a seguir, como origem e essência da justiça e, quando esta medra, o amor e a nobreza, até os graus mais elevados que a visão que ultrapassa o principium individuationis; visão essa que, ao suprimir a diferença entre o próprio indivíduo e os outros, é a única que torna possível e elucida a plena bondade de disposição (Güte der Gesinnung) até o amor desinteressado e o mais generoso autosacrifício pelos outros ${ }^{49}$.

A compreensão da inutilidade do esforço direcionado à satisfação da vontade, que se dá, todavia, em configurações volitivas elevadas, mesmo que pautadas em uma intuição do princípio metafísico do mundo, ainda consistem em percepções parciais da sua infinitude, mas com desdobramentos práticos significativos ante o egoísmo imanente ao mundo. Elevação moral apenas é possível por meio do ultrapassamento do mundo fenomênico. Essa capacidade de reconhecer a identidade da vontade que afasta o homem do sofrimento mais direto e sua vontade se volta para a negação da representação corpórea, intuitiva, para a ascese, para o autossacrifício ${ }^{50}$. O traço abstrato da compreensão schopenhaueriana implica que todas as tomadas de atitude e redirecionamentos da vontade se

47 Que de forma elevada potencializa as coisas, esquecendo de si mesmo e compreendendo o mundo de forma puramente objetiva, tornando mais belas as coisas, na medida em que a consciência de si desaparece. SCHOPENHAUER, WWV II/MV II, 30, p. 428.

48 Idem, p. 429.

49 SCHOPENHAUER, WWV I/MVI $\S 68$, p. 487.

50 SCHOPENHAUER, WWV I/MV I $\S 68$, p. 489. 
pautam em uma representação que não é falsa, dado o seu cunho intuitivo e corpóreo, mas não decisivamente verdadeira. Neste sentido, o egoísta, infinitamente distante do conhecimento da essência do mundo e da consequente inutilidade de seus esforços, mas também as figuras mais elevadas, até o sujeito do conhecimento, são norteadas por uma representação jamais verdadeira. $\mathrm{O}$ mesmo se aplica a casos moralmente reprováveis como no do suicídio e no assassinato do filho pelo pai, pautados na ilusão da possibilidade supressão do sofrimento a partir da supressão da aparência. A diferença entre estes casos é que o asceta constrói para si a ilusão segundo a qual os seus sofrimentos e privações são preferíveis ao sofrimento egoísta ${ }^{51}$. Também neste caso, a intensão de diminuir os tormentos mantém o seu caráter ilusório, que, por si só é, necessariamente, também vontade, onipotente e inalterada e que no homem se manifesta na ideia de liberdade, a qual possibilita uma visão elevada da vida (das Ganze des Lebens übersehen lässt) e independente da impressão do momento ${ }^{52}$.

Desse modo, para Schopenhauer, o conhecimento pode ser aproximado da fé (Glauben) ${ }^{53}$, mas que "implica que o nosso estado originário é essencialmente sem cura (heilloser), em relação ao qual, portanto, precisamos de redenção (Erlösung)", que só pode ocorrer por meio da fé, isto é, "por um conhecimento alterado (veränderte Erkenntniss) e essa fé mesma só pode se dar mediante a misericórdia (Gnade)", que nos é exterior, o que significa que a salvação nos é estranha e que o seu sentido indica o voltar-se para a negação e para o abandono (Aufgebung) da pessoalidade $^{54}$ e do que ela pressupõe, do princípio de razão, da identificação identitária e da coerência causal. Ao aproximar a sua filosofia prática dos dogmas cristãos e védicos, Schopenhauer é cônscio da dimensão simbólica inerente a ambas as religiões, o que para ele parece atenuar a possibilidade de que isso venha a significar uma restrição do imprescindível traço imanente de sua filosofia ${ }^{55}$, pois o mundo, se pautado apenas na percepção direta da vontade, seria para o homem intolerável e a vida um

51 SCHOPENHAUER, WWV II/MV II 49, p. 707.

52 SCHOPENHAUER, WWV I/MV I $\$ 70$, p. 519.

53 Idem, p. 523.

54 SCHOPENHAUER, WWV I/MV I $§ 70$, p. 523.

55 Que busca coadunar os aspectos concretos e abstratos. 
inferno, portanto, impossível. Portanto, a ideia da negação da vontade de vida não pode pressupor a aniquilação completa da vontade, mas é formulada como uma tentativa de fornecer uma explicação isenta de contradição imanente dos fenômenos da genialidade, da santidade e do elevado homem do conhecimento. As dificuldades de sua exposição advêm dos pressupostos metafísicos que Schopenhauer mobiliza para justificá-la, haja visto que o mundo não pode deixar de ser vontade e uma supressão do querer não é possível, mesmo que seja do querer o nada querer, ou querer o nada, consistindo ela em uma noção não compatível, com pressupostos referenciais imanentes. No tópico final do quarto livro de MVR, Schopenhauer registra este aspecto ao mencionar que o conceito de Nada (NICHTS) é relativo e se refere apenas a algo que ele nega. Desse modo, continua ele: "considerado com mais proximidade, não é nenhum nada absoluto", pois "todo nada enquanto tal é apenas pensado em uma relação com algo outro e pressupõe, assim como o próprio outro, esta relação" 56 . A relatividade e a relação do nada com aquilo que a que ele se opõe como grandeza negativa é o mundo da representação, ao mesmo tempo objetivação da vontade e produto do sujeito.

O comumente tomado (Angenommene) como positivo, que nós chamamos de EXISTENTE (SEIENDE) e cuja negação o conceito Nada em sua significação mais geral expressa, é precisamente o mundo da representação, que eu demonstrei ser objetividade da vontade, seu espelho (Spiegel). [...] Negação, supressão, alteração da vontade é também supressão e desaparecimento do mundo, seu espelho ${ }^{57}$.

Portanto, o nada precisa ser pensado para além das leis do pensamento referencial, muito embora Schopenhauer deseje permanecer no terreno da filosofia e por isso é possível se ater ao contrassenso (Unsinn), como forma de ultrapassar o sentido estabelecido pela necessidade lógica. Expressar essa ideia só é possível como não conhecimento, como experiência (Erfahrung) intransmissível, portanto exterior à estrutura cognitiva da consciência, aproximando-se de uma experiência mística que para

56 SCHOPENHAUER, WWV I/MV I 771, p. 525.

57 SCHOPENHAUER, WWV I/MVI $\$ 71$, p. 526. 
ele está associada ao quietismo e ao ascetismo ${ }^{58}$. Esta precisa ser pensada para além da forma identitária e sequencial da representação, necessidade para qual o principal obstáculo é a vontade em sua manifestação vital, enquanto querer viver (Leben wollen). Neste ponto Schopenhauer articula uma forma de conhecimento não referencial, o conhecimento da nulidade da identidade ante a vontade, cujo efeito é aproximado da arte de Rafael e Correggio e associado a uma consideração (Betrachtung), tomada como única forma de consolo (Trost) ante o sofrimento inerente ao mundo e como forma de permanecer na serenidade da negação da representação.

Muito embora o nada filosófico de Schopenhauer não seja um mito ou discurso religioso vazio, ao levar a um estado de liberdade com respeito a representação ele se torna uma percepção não conceitual da própria vontade, que na sua infinitude e absoluta liberdade, é tudo e nada. O nada pode assim ser tomado como uma experiência mística ${ }^{59}$ e, enquanto tal, estética.

Para a negação da própria vontade a representação de que se submete e se rende totalmente e sem apoio a uma vontade outra e exterior é um meio de alívio psíquico e, por isso, um veículo alegórico adequado da vontade ${ }^{60}$.

\section{A recepção da Perspectiva Imanentista de Schopenhauer por Nietzsche}

A recepção da filosofia de Schopenhauer por Nietzsche, em sua obra inicial e nos textos em que este encontrava-se envolvido com a arte wagneriana, é bastante conhecida e tema de inúmeros trabalhos. Todavia, mesmo que seja mencionada a posterior ruptura com ambos (BARROS, 2007, p. 88), um afastamento por completo de posições que remetem a Schopenhauer não pode ser afirmado ${ }^{61}$.

Especificamente no que se refere a temas que em Nietzsche estão relacionados a perspectivas fisiopsicológicas, a influência schopenhaueriana é bastante significativa. Isso implica em uma assimilação

58 SCHOPENHAUER, WWV II/MV II $\S 48$, p. 712.

59 HANNAN, 2009, p. 120.

60 SCHOPENHAUER, Parerga II, XIV, § 169, p. 284.

61 GEMES, 2012, p. 283. 
crítica do caráter representacional, em Nietzsche perspectivístico, de toda reflexão humana ${ }^{62}$. Todavia, em lugar de ficar preso em uma interpretação cética ou optar por uma posição metafísica como forma de superação deste limite, Nietzsche, influenciado por uma nova configuração do horizonte científico do seu tempo, busca verter a compreensão deste aspecto em um pressuposto motivador. Interessado pela física teórica de Rugero Boscovich, ele compreende o ultrapassamento de um modelo científico fundado na justificação apenas por dados referenciais sensórios, assim como assimila aspectos da crítica do atomismo filosófico feita pelo jesuíta croata, que neste resulta em uma negação da matéria e em Nietzsche em uma nova "teoria da realidade" ${ }^{63}$. A partir disso, a coerência presumida pelas formas de representação próprias do intelecto humano propostas por Kant não é negada, mas têm o seu valor restringido e noções advindas desse pressuposto se tornam objetos de crítica do filósofo, tais como as noções de matéria e de identidade. Em Nietzsche a estrutura representacional do intelecto humano está, como para Schopenhauer, condicionada pelo organismo da qual ela é expressão tardia e por isso ela não pode ser mencionada como marco de determinação dos limites do conhecimento. As insuperáveis inclinações à identificação identitária e à compreensão causal não podem ser superadas por serem necessidades fisiológicas com repercussões psicológicas ${ }^{64}$, mas devem ser consideradas e relativizadas dado suas características perspectivísticas ${ }^{65}$. A complexidade da efetividade ultrapassa em muito estes pressupostos elementares ${ }^{66}$, superficiais ${ }^{67}$, de compreensão e, deste modo, é necessário ir além deles, pois "nós formamos o nosso conhecimento" e é precisamente o desconhecimento que produz um mundo fantasioso (geträume Welt) ${ }^{68}$ ao qual pertencem

62 Freidrich Kaubach indica a origem kantiana do perspectivismo do qual Nietzsche na sua interpretação é legatário, porém acentua que a inserção das questões pulsional e corpórea na problematização do conhecimento distancia o perspectivo de Nietzsche do de Kant (KAUBACH, 1990, p. 227).

63 WHITLOCK, 1996, p. 204.

64 NIETZSCHE, KSA 2, MAM/HHI $\$ 9$, p. 29.

65 NIETZSCHE, KSA 2, MAM/HHI"prefácio"§6, p. 20.

66 NIETZSCHE, KSA 3, FW/GC $\$ 57$, p. 421-2.

67 NIETZSCHE, KSA 3, M/A § 125, p. 117.

68 NIETZSCHE, KSA 3, M/A § 118, p. 111.

Rev. Filos., Aurora, Curitiba, v. 30, n. 49, p. 173-204, jan./abr. 2018 
as formulações metafísicas. Isso implica a necessidade de concepção e experimentação de novos pressupostos e modelos interpretativos.

Presa a conexões lógicas causais intuitivas próprias do entendimento, uma ampliação do conhecimento do mundo não apenas não é possível, como nela é facilmente possível se enclausurar moralmente, como pode ser demonstrado em toda a tradição metafísica, presa às ideias de identidade e de estabilidade. Uma lógica especulativa que vá além destes parâmetros inferenciais pode obter resultados demonstráveis bastante diferentes das conclusões intuitivas ${ }^{69}$, mas que, todavia, deve tomar o cuidado de não se deixar seduzir pela inclinação valorativa que pressupõe a possibilidade da existência da verdade ${ }^{70}$. Para Nietzsche foi o fim da crença na verdade enquanto algo efetivo oriunda da linguagem e mantida pela tradição metafísica ${ }^{71}-$ que levou $^{2}$ o conhecimento à negatividade e à tendência de negar o mundo. As dicotomias "verdade x falsidade", "conhecimento x desconhecimento", "ser x não ser", que são para Nietzsche decisivamente valorativas e sem significação real, jamais tiveram o seu estatuto colocado em questão, dada a grande importância prática das mesmas ${ }^{72}$, que possibilitou o erigir de toda uma estrutura valorativa que norteou a cultura ocidental desde Platão. São as ciências, distanciadas da metafísica e de sua moral, que fornecem os resultados determinantes para a identificação destas noções como valorativas e, portanto, para a superação delas ${ }^{73}$.

É a partir da assimilação de uma perspectiva imanentista da filosofia que possibilita Nietzsche confrontar as conclusões lógicas dos pressupostos metafísicos com a efetividade ${ }^{74} \mathrm{e}$, por meio de uma perspectiva fisiopsicológica ${ }^{75}$, argumentar que o desejo por estabilidade e identidade é próprio do perspectivismo do intelecto humano ${ }^{76}$ e não um dado efetivo do mundo. Mesmo quando Nietzsche inicia o seu

69 NIETZSCHE, KSA 3, FW/GC § 357, p. 599.

70 NIETZSCHE, KSA 3, FW/GC $§ 373$, p. 625.

71 NIETZSCHE, KSA 2, MAM I/HH I §11, p. 30.

72 Pois, "até agora foram os erros os poderes mais consoladores (trostreichen)". Nietzsche, KSA 3, M/A § 424, p. 260.

73 NIETZSCHE, KSA 2, MAM I/HHI 1 , p. 23.

74 NIETZSCHE, KSA 6, GD/Cl, A "razão" na Filosofia § 3, p. 76.

75 NIETZSCHE, KSA 5, JGB/BM § 23, p. 38.

76 NIETZSCHE, KSA 3, FW/GC $\$ 111$, p. 471. 
afastamento do wagnerianismo e da recepção deste da filosofia de Schopenhauer, estes aspectos não perdem em significação, eles apenas são mobilizados em favor dos novos direcionamentos de suas reflexões.

\section{A interpretação fisiológica do pessimismo}

A afirmação de Nietzsche em Ecce homo, segundo a qual um aspecto de grande valor (Werthvolles) em seu escrito inicial O nascimento da tragédia havia sido desconsiderado (überhört), precisamente a relação dos gregos (Griechenthum) com o pessimismo, como estes o superaram (überwanden $)^{77}$, possui grande significação quando considerada a contraposição da interpretação dionisíaca do mundo com a cristã. A argumentação que se segue é bastante crítica com relação Schopenhauer, na qual Nietzsche confronta a sua concepção dionisíaca do mundo pautada no pressuposto de uma afirmação deste com o pessimismo, que ele interpreta como parte integrante da cultura ocidental e que, decorrente da posição insustentável socrática, da opção desta pela racionalidade, redundou em uma desvalorização da vida e do mundo e que alcançou significativamente tanto Schopenhauer, quanto Richard Wagner.

Nas reflexões de Nietzsche, cujo pano de fundo é claramente a filosofia de Schopenhauer, são os gregos o tema nuclear ${ }^{78}$ e estes são mobilizados invariavelmente em uma contraposição com o pessimismo moderno. Nietzsche formula a noção de pessimismo da força (Pessimismus der Stärke ${ }^{79}$ para se referir aos helenos, em contraposição ao pessimismo de seu tempo e que implica na pressuposição de que os gregos pré-filosóficos, trágicos, não estavam alheios aos terríveis aspectos da existência, mas de que estes os teriam levado não a uma negação do mundo, mas a sua aceitação, isto possibilitado pelo embelezamento artístico. Como já mencionado, sendo o pessimismo na visão de Nietzsche consequência da desilusão relativa à crença na verdade, que teria levado a cultura

77 NIETZSCHE, KSA 6, EH/EH, p. 309.

78 NIETZSCHE, KSA 1, GT/NT, prefácio §1, p. 11.

79 Idem, p. 12. 
ocidental ao afastamento do mundo enquanto reação às baldadas pretensões e ao esgotamento vital, resultante do esforço infrutífero da busca pela verdade e das consequências não previstas deste anseio, que ele interpreta a possibilidade de sua relativização perspectivista. $\mathrm{O}$ desejo de verdade não pode ser superado, do mesmo modo que a religião e a metafísica, mas elas necessitam ser compreendidas de forma proba, para que as valorações que as sustentam possam ser alteradas. A compreensão do significado do desejo de verdade e de suas dificuldades extrapola então para Nietzsche o âmbito epistemológico e adquire múltiplas dimensões, tais como a fisiológica e a moral, pois "o problema da ciência, não pode ser reconhecido no terreno (Boden) da própria ciência"80.

Sob o ponto de vista moral, a verdade não é uma questão imanente, mas sim valorativa, a sua necessidade não se pauta em um pressuposto demonstrável, mas apenas proposto como necessário. A sua necessidade advém de uma outra ordem, que os antigos gregos trágicos já haviam compreendido, mas que o racionalismo filosófico transmutou em conceito; a necessidade da ilusão, "pois toda vida repousa sobre ilusão, arte, engano, ótica, necessidade do perspectivo e do erro" ${ }^{81}$.

A menção de Nietzsche à necessidade de ilusão traz consigo implicitamente as noções de prazer (Lust) e de desprazer (Unlust), desta forma, é primeiramente fisiológica ${ }^{82}$. Esta via de consideração o leva a uma interpretação fisiológica do pessimismo de seu tempo e o faz indicar que um dos motivos para a tendência de desvalorização da vida se deve a uma forma de exaustão (Erschöpfung), de degeneração (Entartung) dos instintos, de desagregação (Disgregation) da vontade ${ }^{83}$. A constatação do fracasso o projeto metafísico de um conhecimento final - indicado por Kant e reafirmado por Schopenhauer - redundou em um pessimismo negativo, pois ambos não conseguem formular uma alternativa outra para este fracasso, que não continue a se basear em alguma noção de verdade. A negação do mundo é consequência desta insistência temática, que é identificada por Nietzsche como decisivamente valorativa,

80 NIETZSCHE, KSA 1, GT/NT, prefácio § 2, p. 13.

81 NIETZSCHE, KSA 5, JGB/BM §5, p. 18.

82 NIETZSCHE, KSA 2, MAM I/HHI 18, p. 39.

83 NIETZSCHE, KSA 6, GD/Cl, "os quatro grandes erros"§ 3, p. 90. 
mas compreensível por via fisiopsicológica. É a moral que desvaloriza a aparência em favor do "ser", mesmo sem, em momento algum, deixar de apresenta-lo apenas como pressuposto e nunca como evidência. $\mathrm{O}$ ser estável é uma fantasmagoria da razão, mas elucidando como dogma moral, revela as consequências da inversão da visão trágica grega efetuada pela metafísica. A inversão dos valores proposta por Nietzsche pressupõe esta compreensão, mas não pode ser reduzida a uma pretensão de retorno aos helenos ou a pretensão de restauração de uma forma de sensibilidade artística, ambas claramente entendidas como inexequíveis por Nietzsche, dada a hegemonia do pensamento científico.

A pretensão de reestabelecimento de uma perspectiva trágica, que é reformulada e resulta na filosofia sob o "simbolismo grego" 84 de Dioniso, e não pode perder de vista dois aspectos fundamentais, uma compreensão dos traços afirmativos da tragicidade grega, da força estética da fusão do impulso figurativo com a sedução musical, mas, ao mesmo tempo, a compreensão de que o seu reestabelecimento não pode ser alcançado. A tragicidade ressurge em sua filosofia como estímulo vital e em contraposição ao pessimismo niilista, como "a mais extrema contraposição a uma filosofia pessimista" ${ }^{85}$ e por isso o dionisíaco da filosofia de Nietzsche não é o mesmo dos antigos, mas um princípio criativo de afirmação da vida. Por outro lado, dada a impossibilidade do retorno e da restauração de sua sensibilidade artística, a reforma da cultura tendo em vista um reestabelecimento da perspectiva artística trágica apenas é possível de ser cogitada, quando se compreender que o trágico deve ser concebido como a uma perspectiva fisiopsicológica ${ }^{86}$ que implica a força e a coragem de aceitar a existência em sua plenitude, composta de beleza, riscos, felicidades e sofrimentos. Desse modo, o dionisíaco da filosofia de Nietzsche não é mais grego em sentido estrito, pois ele pressupõe mesmo uma negação da metafísica por meio de uma concepção não dogmática e criativa do conhecimento (alegre ciência) ${ }^{87}$, algo ausente do mundo helênico pré-filosófico. O seu sentido

84 "griechische Symbolik". CIIGD, "0 que eu devo aos antigos"§ 4, p. 159.

85 EH/EH/GT/NT § 3, p. 312.

86 NIETZSCHE, KSA 6, GD/Cl"0 que devo aos antigos"§5, p. 160.

87 BARROS, 2016, p. 94. 
mais decisivo é se opor a toda forma de negação da existência, tal como Nietzsche havia compreendido no sentimento externado pela Psiquê de Aquiles no Hades a Ulisses, que antes cogitara as vantagens de um suposto reinado do pelida sobre as demais Psiquês, ao que Aquiles, o mais soberbo humano da épica grega responde:

Não me edulcores a morte, ilustre Odisseu.

Preferiria, vivente, ser empregado em outro lugar, junto a homem sem gleba e com poucos víveres, a reger entre todos os mortos desassomados ${ }^{88}$.

O que Nietzsche apreende dos gregos e quer transpor para a sua filosofia são as forças estéticas e criativas da arte, que na sua perspectiva salva os helenos do pessimismo e os ensina que "o pior de tudo seria para eles logo morrer e o segundo absolutamente morrer" ${ }^{\prime 29}$. É a manutenção em sua filosofia deste princípio, assimilado do aspecto fundante do instinto helênico (Grundthatsache des hellenischen Instinkts), a sua "vontade de viver" (Wille zum Leben) ${ }^{90}$, que o afasta da arte wagneriana e da filosofia de Schopenhauer, compreendidos por ele como símbolos máximos do empobrecimento vital que caracteriza a cultura ocidental em decorrência da metafísica.

\section{A insuperável dimensão simbólica da vida}

Nas reflexões de Schopenhauer e de Nietzsche encontramos duas e talvez as mais amplas e intensas problematizações dos temas da negação e da afirmação do querer, por conseguinte da vida. Em última análise, o que se tentou argumentar aqui foi que em ambos e de forma diferenciada, as perspectivas não podem ser propostas sem que seja pressuposta uma dimensão simbólica que deve funcionar como uma alternativa à

88 HOMERO, 2014, Canto XI, p. 488-491.

89 NIETZSCHE, KSA 1, GT/NT §3, p. 36.

90 NIETZSCHE, KSA 6, GD/CI"o que eu devo aos antigos" § 4, p. 159. 
negatividade inicial que a impossibilidade de um conhecimento último da efetividade poderia significar. Enquanto Schopenhauer ainda se mantém preso a determinados aspectos da filosofia moderna - muito embora indicando claramente aspectos que redundarão no seu distanciamento dela - e assim busca ainda indicar uma saída para idealidade abstrata da reflexão filosófica com sua filosofia metafisico-imanentista, o filólogo Nietzsche mobiliza os gregos pré-filosóficos, míticos, para justificar uma interpretação histórico-genealógica e desconstrutiva da metafísica. Possivelmente, o ponto de maior significação para o distanciamento da sua filosofia para a de Schopenhauer repouse precisamente no fato de que para Nietzsche a metafísica é vista como um problema valorativo, moral, e não como um pressuposto interpretativo efetivo ${ }^{91}$.

Para ele, a alternativa metafísica de Schopenhauer para a questão do reducionismo da interpretação materialista do mundo significa o desconhecimento do conteúdo moral da metafísica, o que teria feito o seu antigo mestre ficar enredado nas malhas da dicotomia entre coisa em si e fenômeno de Kant. Nietzsche supera esta questão com o seu perspectivismo e buscando ultrapassar a limitação cognoscitiva do mundo associada aos limites da faculdade de conhecimento humana, propõe a superação deste pressuposto, tendo em vista postulados das ciências. Isso o leva a indicar o caráter fantasioso das noções de sujeito e de objeto, assim como da necessária vinculação da noção de conhecimento a estes dois pressupostos, a partir do ponto de vista de que a estabilidade presumida neles é apenas uma necessidade fisiológica tornada moral ${ }^{92}$.

Para ele a consciência, que na história animal é supérflua, ocorre no homem por uma "capacidade de comunicação", que evidencia uma "necessidade de comunicação" (Mittheilungs-Bedürftigkeit), pois o homem é o mestre na comunicação e na inteligibilidade de suas necessidades (Verständlichmachung seiner Bedürfnisse) ${ }^{93}$, capacidades que aperfeiçoadas levam à "arte da comunicação" (Kunst de Mittheilung) e que leva aos artistas (Künstler), “Os oradores (Redner), pregadores, escritores,

91 NIETZSCHE, KSA 3 FW/GC $§ 99$, p. 454.

92 NIETZSCHE, KSA 3 FW/GC $\S 373$, p. 625.

93 NIETZSCHE, KSA 3 FW/GC $\$ 354$, p. 591. 
todos homens que chegam no fim de uma longa cadeia"94 a possibilitarem pressupor "que a consciência se desenvolveu apenas sob a pressão da necessidade de comunicação", que ela é propriamente "uma teia de conexão entre homem e homem". Para Nietzsche a consciência decorre de uma existência coletiva, gregária e está diretamente associada às necessidades coletivas e naturais e a sua manifestação é superficial e simbólica. A não compreensão destes aspectos nos fazem ficar presos a noções como sujeito e objeto, que em última análise advém da gramática, a "metafísica para o povo" (Volks-Metaphysik), assim como de "coisa em si" e "fenômeno" (Erscheinung), ao invés de nos fazer perceber que:

Nós não temos nenhum órgão para o conhecer (Erkennen), para a “verdade": nós "sabemos" (ou acreditamos ou imaginamos) precisamente na medida do interesse utilitário do homem de rebanho (Menschen-Heerde), do gênero (Gattung) e mesmo o que é aqui mencionado como "necessidade" é apenas também uma crença, uma imaginação (Einbildung) e talvez um fatal disparate, devido ao qual nós pereceremos ${ }^{95}$.

O conhecimento decorre então da necessidade de tornar o desconhecido conhecido, que pode ser aprofundado e compreendido como necessidade de um "sentimento de segurança" (Sicherheitsgefühls) ${ }^{96}$ e por esse motivo as ciências naturais não podem resolver a questão do conhecimento, pois tomam por objeto apenas o que é exterior, em contraposição à psicologia, que deseja tomar o não estranho (Nicht-Fremde) como objeto, evidenciando a ele os modos de "conhecimento". Devido a isso, se pode conjecturar que ela volte a ser a "rainha das ciências", "a via para os problemas fundamentais (Weg zu den Grundproblemen)" ", pois a sua forma de observação é capaz de revelar tanto o fantasioso nos dogmas filosóficos, mas também os pressupostos intransponíveis de toda interpretação ${ }^{98}$. Ela é indicável por poder desconstruir a verdade ao compreendê-la como padrão psíquico e não como problema

94 lbidem.

95 Ibidem, p. 593.

96 NIETZSCHE, KSA 3 FW/GC § 355, p. 594.

97 NIETZSCHE, KSA 3 JGB/BM § 23, p. 40.

98 NIETZSCHE, KSA 3 FW/GC § 334, p. 575. 
a ser resolvido. Ela evidencia assim a insuperável dimensão simbólica do homem, que tanto na arte, esse "culto ao não verdadeiro" (Cultus des Unwahren $)^{99}$, quanto no pensamento da vigília, necessita da ilusão estável. Não se trata, portanto, nem de um ceticismo negativo, nem de uma destruição de todo critério de conhecimento, mas de um redimensionamento da verdade e do conhecimento ${ }^{100}$, tomados a partir de então como necessidades humanas e não como efetividades. Na filosofia de Nietzsche há uma moral do método ${ }^{101}$ e critérios de justificação do conhecimento, contudo formulados como hipóteses falíveis e trazendo consigo a motivação de sua refutação e aperfeiçoamento. Esta concepção, Nietzsche busca superar integrando o conhecimento à vida biológica não como valor, mas como interesse, e argumenta no sentido de mostrar que a questão central relativa a ele não foi a verdade, mas a utilidade $^{102}$ ou o poderio ${ }^{103}$ desta concepção.

\section{Considerações finais}

A argumentação precedente buscou demonstrar as potencialidades temáticas das filosofias de Schopenhauer e de Nietzsche no que tange a consideração de uma prática simbólica inerente ao homem e que se apresenta como tema de significativa importância na atualidade. Pretendeu-se mostrar como, em ambos os autores, este aspecto se apresenta associado às questões da negação e da afirmação da vontade, mas que estas temáticas se conectam com outros campos temáticos, os quais então tentamos aproximar de abordagens contemporâneas como as de António Damásio e de Yuval Harari. O sentido desta tentativa de aproximação é de mostrar como o pensamento filosófico aqui representado por Schopenhauer e Nietzsche pode constituir importante via reflexiva para consideração de determinadas questões, mesmo compreendendo

\footnotetext{
99 NIETZSCHE, KSA 3 FW/GC §107, p. 464.

100 ABEL, 2010, p. 22.

101 Muito embora não haja um único método para ela. KSA 3 M\A § 432, p. 266.

102 NIETZSCHE, KSA 3 FW/GC $\S 110$, p. 469.

103 NIETZSCHE, KSA 3 M/A § 114, p. 106.
} 
ampliações temáticas e aprofundamentos que os avanços científicos e tecnológicos têm possibilitado nos últimos dois séculos. Mesmo tendo isso em vista, as filosofias dos dois pensadores ainda mantêm o status de posições inovadoras referentes a temáticas contemporâneas ${ }^{104}$, tanto no que concerne a questões morais e gnosiológicas, mas também com respeito à vida na sua mais tácita imanência.

\section{Referências}

ABEL, G. Zeichnen der Warheit - Wahrheit der Zeichnen. Nietzsche - studien. Berlin/New York: Walter de Gruyter, v. 39, 2010. p. 17 -38.

BARBOSA, J. Negação da vontade e significado moral do mundo, em: Carvalho, Costa \& Motta (Org.): Nietzsche - Schopenhauer: Metafísica e significação moral do mundo. Fortaleza: Ed. UECE, 2015. p. 177-190.

BARROS, R. A. P. Kunst und Wissenschaft bei Nietzsche. Von menschliches, Allzumenschliches bis Also sprach Zaratustra. Berlin: Parerga verlag, 2007.

BARROS, R. A. P. Nietzsche: Além-do-homem e idealidade estética. Campinas: Editora PHI, 2016. p. 94.

CARUS, D. E. Die Gründung des Willensbegriffs. Die Klärung des Willens als rationales Strebevermögen in einer Kritik an Schopenhauer und die Ergründung des Willens in einer Auseinandersetzung mit Aristoteles.Viesenbaden: Springer VS, 2016.

DAMÁSIO, A. E o cérebro criou o homem. Trad. Laura Teixeira Motta. São Paulo: Companhia das Letras, 2011.

DARWIN, C. On the Origin of Species. In: Evolutionary Writings. Edited by James A. Secord. New York: Oxford, 2008.

FONSECA, E. R. Uma estreita passagem: O conceito de corpo nas obras de Schopenhauer e Freud. Curitiba: Editora UFPR, 2016.

104 Expande-se aqui a interpretação de Dirk Göhmann a Nietzsche. Conf. GÖHMAN, 2014, p. 353. 
GEMES, K.; JANAWAY, C. Life-denial versus Life Affirmation. Schopenhauer and Nietzsche on Pessimism and Ascetism. In: edited by Bart Vandenabeele (Org.) A Companion to Schopenhauer. Shushester (UK): Blackwell Publishing Ltd., 2012. p. 280-299.

GÖHMANN, D. Neurophilosophie. In: Koßler, M. Shubbe, D. (Org): Schopenhauer Handbuch: Leben - Werk - Wirkung. Frankfurt: J. B. Metzler, 2014. p. 343-346.

HANNAN, The Riddle of the World. A Reconsideration of Schopenhauer's Philosophy. New York: Oxford University Press, 2009.

HARARI, Y. N. Sapiens - Uma breve história da humanidade. Trad. Janaína Marcoantonio. Porto alegre: L\&PM, 2014.

HOMERO. Odisseia. Trad. Christian Werner. São Paulo: Cosac Naify, 2014.

KAULBACH, F. Philosophie des Perspektivismus. Tübingen: J.C.B. Mohr, 1990.

NIETZSCHE, F. Friedrich Wilhelm. Sämtliche Werke. Kritische Studienausgabe (KSA). Ed. G. Colli e M. Montinari. Munchen, de Gruyter/DTV, 1980.

SCHOPENHAUER, A. Werksausgabe. Zürich: Haffmans Verlag, 1987.

SCHOPENHAUER, A. O mundo como vontade e representação. Trad. Eduardo Fonseca. Paraná: Editora UFPR, 2014. Tomo II.

WHITLOCK, G. Roger Boscovich, Benedict Spinoza and Friedrich Nietzsche: The untold Story. Berlin/New York: Walter de Gruyter. Nietzsche Studien 25, 1996. p. 200-219.

Recebido: 19/01/2018

Received: 01/19/2018

Aprovado: 05/02/2018

Approved: 02/05/2018 